\title{
Condicionamento gengival visando o perfil de emergência em prótese sobre implante
}

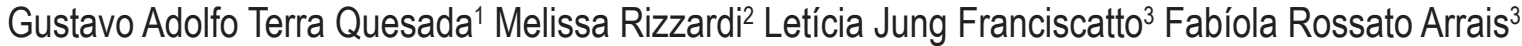

\begin{abstract}
RESUMO
A procura por um resultado que alie função e estética satisfatória vem se tornando uma exigência cada vez maior quando se trata de uma reabilitação de próteses implanto-suportadas. Muitos pontos críticos desse processo vêm sendo solucionados através do conhecimento para um correto posicionamento dos implantes. Uma adequada manipulação dos tecidos moles, além de um apurado trabalho protético torna-se essenciais em áreas estéticas. 0 objetivo deste trabalho é contrastar, através de uma revisão de literatura, algumas técnicas de condicionamento gengival visando a um perfil de emergência. Concluiu-se que um plano de tratamento bem realizado, um eficaz controle de placa bacteriana, além de uma preparação meticulosa da área doadora, receptora e suturas, constituem pré-requisitos fundamentais para o sucesso da terapia. Logo, existem diferentes etapas onde se pode intervir nos tecidos periimplantares: antes da colocação dos implantes, simultaneamente à colocação dos mesmos, durante a fase de osseointegração e na reabertura dos implantes.
\end{abstract}

Descritores: Estética; Prótese Dentária; Implantes Dentários.

\section{Gingival conditioning in order to make the emergence profile on implant-supported prostheses}

\begin{abstract}
The search for a result that satisfactorily combines function and aesthetics, is becoming an increasingly pressing need when it comes to rehabilitation of an implant-supported prostheses. Many critical points of this process have been solved by the knowledge for the correct positioning of the implants. Soft tissue management and an accurate prosthetic work have been shown very important in the aesthetics areas. The focus of this work is to compare some techniques of gingival conditioning based on a specific literature review. Completes that a well executed treatment, an effective hygiene and a meticulous preparation of the recipient site, donor site, graft and suture, constitute a fundamental requirement for a successful therapy. Thus, commonly there are different stages where you can step in peri-implant tissues: before or simultaneously the installation of implants, during the period of osseous integration and in the re-opening of implants.
\end{abstract}

Descriptors: Esthetics; Dental Prosthesis; Dental Implants.

\footnotetext{
${ }^{1}$ Doutor em Odontologia pela Pontifícia Universidade Católica do Rio Grande do Sul (PUCRS), Porto Alegre, RS, Brasil.

${ }^{2}$ Especialista em Implantodontia pela Universidade de Maringá (UNINGÁ-SM), Santa Maria, RS, Brasil.

${ }^{3}$ Graduada em Odontologia pela Universidade Federal de Santa Maria (UFSM), Santa Maria, RS, Brasil.
} 


\section{Introdução}

A odontologia atual vive uma constante busca da excelência estética, funcional e biológica em todos os seus segmentos, para pacientes que se tornam cada vez mais diferenciados, que freqüentemente, depositam uma grande expectativa no que tange ao resultado estético final de seu tratamento.

Em implantodontia, para conseguirmos um resultado estético próximo ao natural, é necessário um correto manuseio dos tecidos moles. É importante a forma, o contorno, o limite cervical, o perfil de emergência da coroa implantosuportada e a qualidade e quantidade de mucosa periimplantar.

Sabe-se que, altura e a espessura do osso alveolar são mantidas graças à permanência das raízes dentais dentro de seus alvéolos e que, após exodontias, é comum ocorrerem reabsorções do rebordo alveolar. Este tipo de alteração pode resultar em prejuízo estético, devido à perda da harmonia do contorno alveolar1.

Um protocolo cirúrgico bem realizado associado a exames pré-operatórios e um plano de tratamento correto, constituem um pré-requisito para o sucesso do futuro resultado do tratamento com implantes. A instalação de implantes dentro da posição ideal, tanto no aspecto mésio-distal como no aspecto vestíbulo-lingual é de fundamental importância².

Os procedimentos de condicionamento gengival podem ser efetuados previamente, durante ou após a instalação dos implantes, com o intuito de maximizar os resultados estéticos dos tecidos moles periimplantados.

A fase de modelamento gengival pelos provisórios, secundária à reabertura, visa contribuir para a conquista de uma adequada harmonia entre os tecidos moles e o perfil de emergência da futura prótese cerâmica definitiva.

A presente pesquisa bibliográfica pretende contrastar técnicas de condicionamento gengival para formação da papila intermediária e reconstituição do arco côncavo gengival. Foi realizada uma revisão da literatura selecionando referências atuais e clássicas por alunos que depois foram revistas pelo orientador, chegando ao consenso das conclusões.

\section{$\underline{\text { Revisão }}$}

O principal fator para o sucesso do condicionamento gengival é um controle de placa severo, caso contrário, perdese 0 controle sobre o direcionamento gengival, devido ao processo de inflamação que se instala no local. Desse modo, somente em um paciente devidamente orientado, estimulado, e que consiga atingir a eliminação da placa bacteriana, é que deve se iniciar o condicionamento ${ }^{3}$.

$O$ aspecto e a avaliação do volume do tecido mole permite prever as necessidades de aumentar o tecido e a escolher técnicas e sequencias de tratamento mais apropriado ao restabelecimento do perfil anatômico correspondente ao sorriso do paciente. Através de um bom planejamento podemos indicar as manobras cirúrgicas necessárias. Em 9 casos de indivíduos insatisfeitos com próteses removíveis, que possuíam perdas dentárias anteriores, foram realizados os planejamentos onde em todos os casos, foram realizados enxertos ósseos, e posteriormente, após a colocação do implante, foram planejados enxertias e condicionamento gengival, sempre enfatizando que o controle de placa é fundamental para o sucesso da terapia. Os enxertos foram realizados com osso autógeno e uso de membrana de colágeno².

A exigência estética varia de um paciente para outro, e o resultado estético depende da forma, do contorno, do limite cervical, do perfil de emergência da restauração implanto suportada e da qualidade e quantidade da mucosa periimplantar6. Um resultado estético muito satisfatório é freqüentemente difícil de ser obtido.

As manipulações de tecido mole disponíveis podem resolver uma grande quantidade de problemas estéticos. Por exemplo, o enxerto de tecido conjuntivo pode reparar defeitos menores no rebordo, restaurar contornos originais pelo aumento da altura e espessura dos tecidos moles. Na região anterior da maxila, ou quando o paciente percebe ser esteticamente importante, o posicionamento do implante será determinado pela necessidade de maximizar tanto a estética quanto a função pela necessidade das restaurações suportadas por implantes. Alguns fatores devem ser estudados no pré-operatório como: linha do sorriso, suporte labial, simetria facial, quantidade e qualidade de tecidos moles, perfil de emergência, tipo de componentes protéticos a serem usados e contorno futuro da restauração final ${ }^{7}$.

A aplicação de técnicas de carga imediata pode auxiliar no resultado estético final. Com essa técnica evita-se uma manipulação excessiva dos tecidos, pois não precisa de cirurgia de reabertura, ocorrendo a cicatrização dos tecidos moles ao redor da prótese provisóriå . 
A necessidade de tecido ceratinizado em torno dos implantes na reabilitação oral é ainda um pouco controversa no que diz respeito ao seu sucesso a longo prazo ${ }^{9}$. A mucosa ceratinizada não é indispensável para a manutenção do tecido periimplantar, quando há uma adequada higienização oral. A forma e a quantidade de tecido ceratinizado podem ser alcançadas ou ampliadas antes, durante ou após a inserção dos implantes.

Aimplantação imediata em alvéolos frescos pós-extração é uma opção terapêutica muito utilizada em áreas estéticas. A possibilidade de substituição imediata de um dente comprometido por um implante aumenta consideravelmente a aceitação do procedimento por parte dos pacientes, uma vez que diminui o número de procedimentos cirúrgicos ${ }^{10}$.

Para conseguirmos uma adequada estética gengival em implantes unitários imediatos a melhor maneira é a confecção de restauração temporária fixa sobre o implante, copiando a arquitetura gengival original circundante ao dente natural. O provisório confeccionado previamente no modelo promove uma transferência fiel da posição do dente, bem como do relacionamento deste com o tecido gengival. Para a otimização da estética a plataforma do implante deve ficar $2 \mathrm{~mm}$ aquém da margem gengival. As vantagens da colocação imediata de implantes são: menor tempo de trabalho, preservação do contorno gengival e oportunidade para um posicionamento axial mais ideal do implante ${ }^{11}$.

A preservação de papilas é um dos maiores desafios da implantodontia, já que há pouca irrigação sanguínea entre implantes e um menor número de estruturas de suporte do periimplante em relação ao periodonto. As incisões conservadoras, realizadas com Punch permitem um melhor contorno da mucosa, tempo cirúrgico menor devido à ausência de suturas e maior estabilidade dimensional dos tecidos duros e moles devido à ausência de retalho mucoperiostal ${ }^{12}$

Em um estudo clínico em 2009, foi descrito o uso da técnica de pressionamento dos tecidos como altamente satisfatória tanto estética quanto funcionalmente para alcançar a remodelação e readaptação tecidual ${ }^{13}$. Dessa forma, a aplicação de uma pressão poderia criar a ilusão de estar o pôntico emergindo dos tecidos e a formação de "pseudo" papilas interdentais que proporcionam um efeito mais natural ao sorriso.

Em 2007, foi avaliada a estabilidade de enxertos gengivais posicionados em torno de implantes dentais no segundo momento cirúrgico (reabertura) ${ }^{14}$. Quatorze pacientes com implantes cobertos por inadequada mucosa queratinizada foram estudados e submetidos à cirurgia plástica periimplantar onde enxertos gengivais autógenos foram utilizados de acordo com a situação clínica presente. Os pacientes foram avaliados com até 12 meses de pós-operatório e os dados sugerem que a cirurgia plástica periimplantar no segundo estágio cirúrgico pode resultar em aumento da espessura da mucosa, especialmente quando realizada em áreas onde a mucosa apresenta um fenótipo delgado.

A harmonia gengival é um importante elemento na estética do sorriso. Os profissionais precisam ter o conhecimento essencial para criar um perfil de tecido mole ideal ao redor de dentes naturais e implantes dentários. Em 2010, através da descrição de dois casos clínicos ${ }^{15}$, foram descritos os requisitos para uma arquitetura gengival ideal e as técnicas utilizadas (enxerto gengival), para alcançar este objetivo, assim como as suas limitações. De acordo com as suas conclusões, a estética gengival irá depender de múltiplos fatores como saúde, quantidade, qualidade, simetria e equilíbrio do tecido mole residual. O manejo cuidadoso dos tecidos moles, associado à adesão aos princípios biológicos e estéticos, irá aumentar a probabilidade de obtenção de resultados satisfatórios.

Pressão gradual: A pressão gradual baseia-se na utilização da restauração provisória para se conseguir 0 condicionamento gengival5. A força de pressão exercida sobre a área deve ser avaliada, pois uma pressão excessiva pode inflamar e até ulcerar o local, ou mesmo uma pressão pequena pouco pode ter influência sobre a área, aumentando a duração do prazo para se conseguir o direcionamento da gengiva. Ela está indicada para áreas pequenas, com espaços de um até dois pônticos, de modo que não se perca o controle sobre as áreas condicionadas. A prótese provisória, feita em resina acrílica, deve pressionar o tecido gengival de modo a modelá-lo, obtendo uma correta relação entre a gengiva e a prótese. Desta maneira, a demanda funcional é atingida, promovendo acesso para higienização e garantindo estética, sendo este um dos objetivos da prótese definitiva (Ver Figura 1) 
Figura 1 -A. Instalação da restauração provisória; B. Condição inicial do tecido gengival; C. Relação da restauração provisória (dentes 11, 12 e 13) com o tecido gengival após condicionamento com pressão gradual; D. Condição final do tecido gengival após condicionamento com pressão gradual.

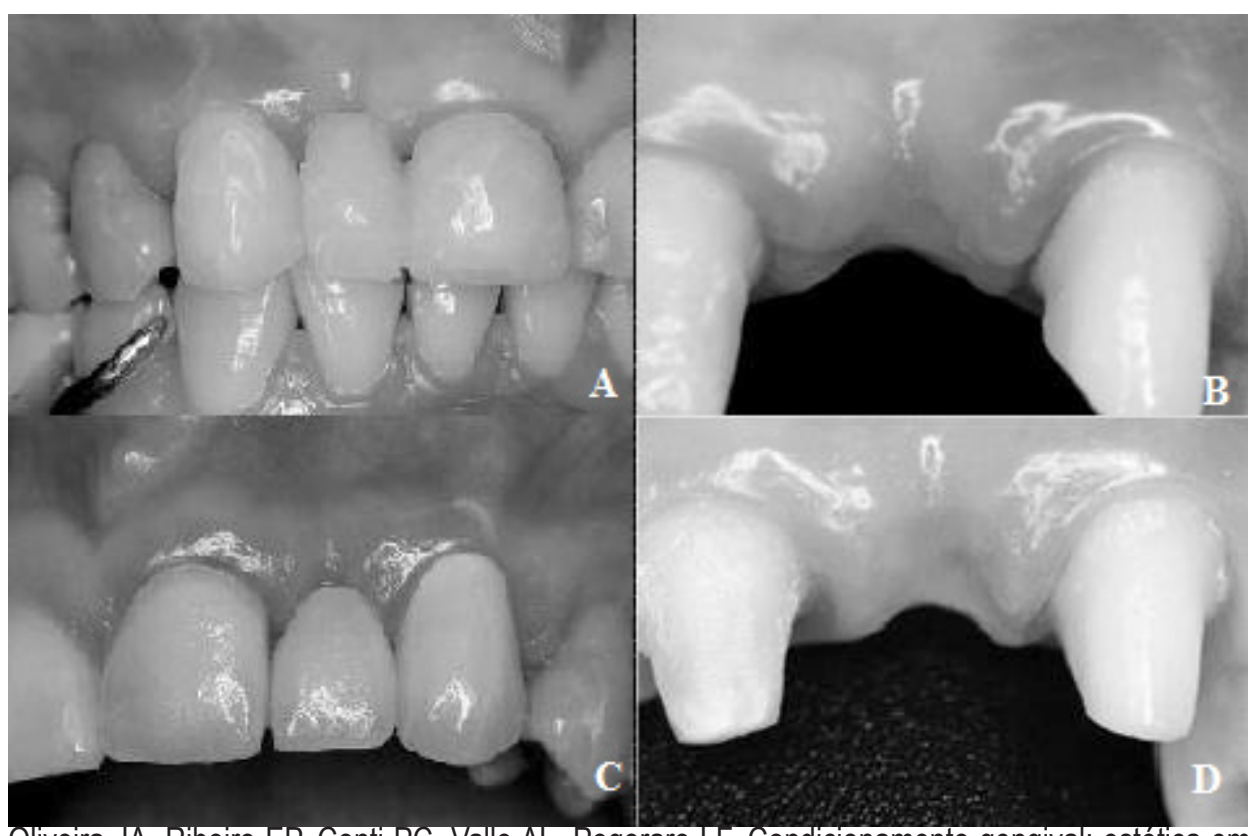

Oliveira JA, Ribeiro EP, Conti PC, Valle AL, Pegoraro LF. Condicionamento gengival: estética em tecidos moles. Rev Facul Odont Bauru. 2002; 10(2): 99-104.

A coroa dental provisória, instalada até 48 horas após o procedimento cirúrgico, deverá permanecer em infra-oclusão durante o período cicatricial para evitar micromovimentos maiores que 150 micrômetros, o que poderia interferir no processo de osseointegração ${ }^{16}$.

Escarificação: A escarificação baseia-se, também, nos princípios biológicos e funcionais da prótese definitiva. Ela está indicada para áreas de mais de um pôntico, pois permite um maior controle sobre áreas extensas, proporcionando maior estética ${ }^{5}$. A escarificação é desenvolvida adaptando-se a restauração provisória nos pilares, delimitando com um lápis o desenho gengival que se é esperado, tomando cuidado para que a tintura do lápis não pigmente o tecido conjuntivo que será exposto. Logo após, faz-se a aplicação de anestesia terminal infiltrativa na área a ser esculpida. O tecido gengival é então esculpido por brocas diamantadas em forma de pêra, em alta rotação com írrigação, criando papilas interdentais, um arco côncavo regular e as concavidades que receberão os pônticos. (Ver Figura 2)

Figura 2 - A. Condição inicial do tecido gengival com marcação guiada pela restauração provisória para realização da escarificação; B. Início da escarificação em alta rotação com broca em pêra sob irrigação no tecido gengival; C. Condição do tecido gengival escarificado; D. Condição final do tecido gengival condicionado pela escarificação.

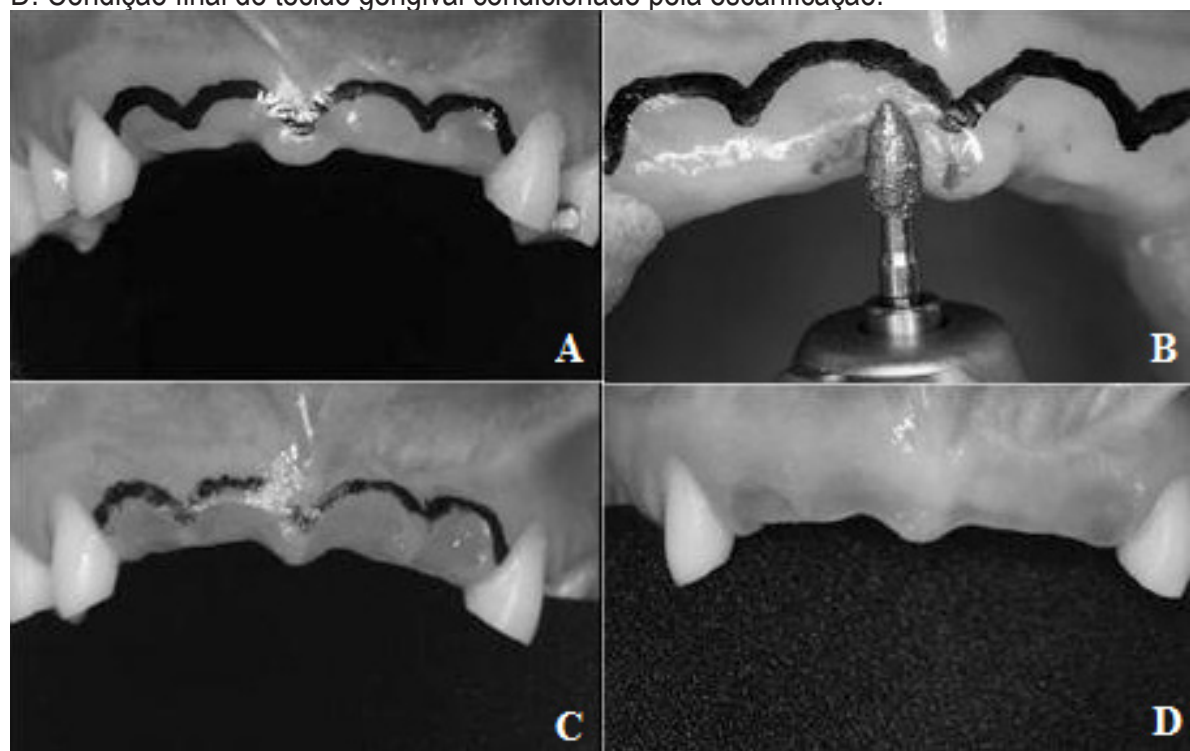

Oliveira JA, Ribeiro EP, Conti PC, Valle AL, Pegoraro LF. Condicionamento gengival: estética em tecidos moles. Rev Facul Odont Bauru. 2002; 10(2): 99-104. 
Técnica da dobra cirúrgica: Essa é uma técnica de manipulação dos tecidos moles, que permite um ganho de volume e contorno estético, sem a necessidade de enxertos gengivais ou ósseos ${ }^{17}$. Essa técnica é feita através da aplicação de uma dobra cirúrgica gengival no momento da reabertura do implante, para colocação de um cicatrizador ou de um componente protético ou uma coroa provisória. Com uma lâmina de bisturi 15c, faz-se incisão no sulco gengival dos dentes vizinhos à área a ser aberta e outra incisão horizontal deslocada para palatina. Esta deverá ser feita a fim de obter tecido queratinizado do palato; sendo que o deslocamento desta incisão dependerá do quanto se necessita ganhar em volume pela vestibular, medição esta feita com régua milimetrada em um modelo de gesso ou na própria cavidade oral onde se estenderá a incisão para palatina, de acordo com a quantidade de tecido medido da depressão vestibular. Desloca-se um retalho de espessura total. Coloca-se o cicatrizador selecionado ou componente protético e provisório. Sutura-se o retalho obtido do palato, pela vestibular, com pontos em forma de suspensório para cada lado proximal (Ver Figura 3). Foi observado que se pode aumentar o ganho final de volume gengival, através de incisões relaxantes na vestibular, sendo que incisões pequenas concentram o ganho de volume na região coronal, enquanto que incisões maiores aumentam o volume em quase toda altura do processo alveolar e aumentam também a faixa de gengiva ceratinizada. É fator também de relevância a forma de suturar este tecido deslocado, sendo que suturas de contenção são indicadas tendo como entrada e saída a vestibular do tecido gengival.

Figura 3 - Técnica da dobra cirúrgica.

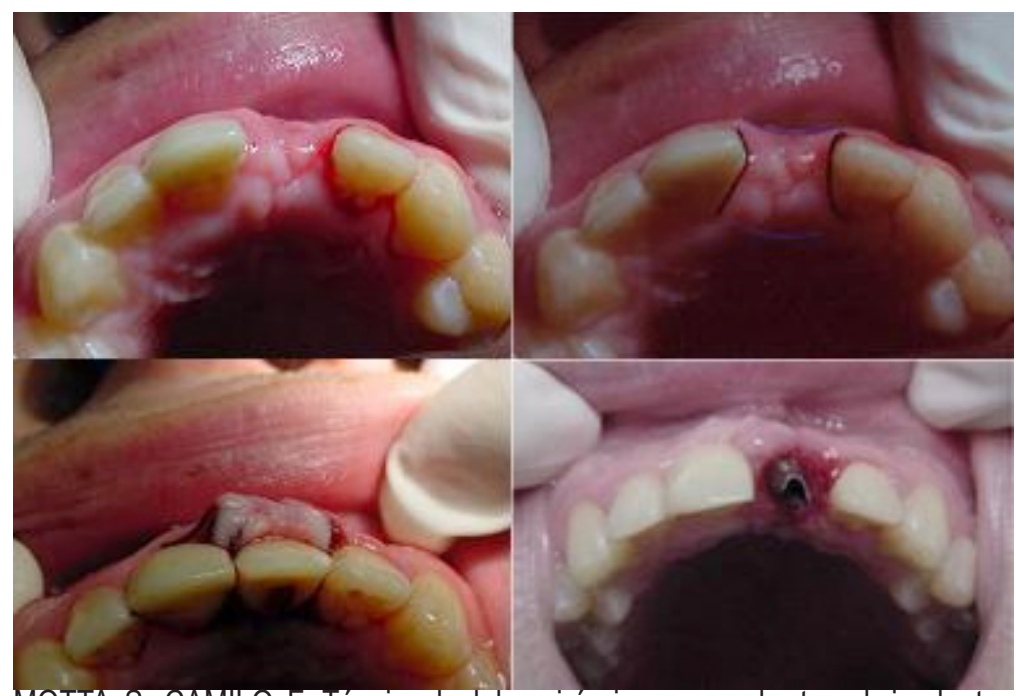

MOTTA, S.; CAMILO, F.; Técnica de dobra cirúrgica para reabertura de implantes osseointegrados;Rio de Janeiro.[capturado em Nov. 2007] Disponível em www. clivo.com.br/pdf/dobra_cirur.pdf.

As seguintes considerações foram salientadas para se garantir o sucesso da técnica: 1) profundidade do sulco rasa do dente adjacente ao rebordo desdentado; 2) deve existir uma zona de gengiva ceratinizada ao rebordo do dente adjacente de forma a suportar procedimentos cirúrgicos e restauradores; 3 ) deve existir uma adequada quantidade e qualidade tecido mole na área desdentada para permitir elevação desejada e espessura do retalho suficiente para prevenir perfuração e para adicionar rebordo; 4) divisão do retalho muco-gengival deveria ser cuidadosamente confinada a área do defeito e o pedículo de tecido conjuntivo posicionado se excessiva pressão para prevenir necrose ${ }^{18}$.

Técnica de Nencovsky: Nessa técnica é feita uma incisão em forma de "U", inicialmente dentro do sulco gengival dos dentes adjacentes, estendendo-se pelo palato um pouco atrás de onde estão localizados os parafusos de cicatrização". Nesse momento é confeccionado um retalho total, levemente elevado com um destaca periósteo e deslocado de palatino para vestibular. As papilas interproximais dos dentes adjacentes são desepitelizadas para receber esse retalho. Nesse momento, o parafuso de cicatrização é movido e trocado pelo intermediário, que uma vez colocado, faz-se uma incisão no meio do retalho deslocado. Cada metade do retalho é colocada sobre as papilas adjacentes previamente desepitelizadas, e, então, suturadas na palatina com suturas verticais ${ }^{19}$.

Técnica de Palacci e Ericsson: Essa técnica cirúrgica inicia-se com uma incisão linear na região do palato ou na lingual, um pouco abaixo de onde estão localizados os cicatrizadores, seguindo-se uma incisão vertical na vestibular, em direção divergente, para dar maior suprimento sanguíneo ao retalho. Eleva-se, então, um retalho total em direção 
vestibular, descobrindo os cicatrizadores, que são substituídos pelos intermediários. Nesse momento, no próprio retalho elevado por vestibular, faz-se uma incisão biselada semilunar ou em "C" na região distal de cada intermediário, formando, assim, um pedículo gengival que será deslocado $90^{\circ}$ para mesial e localizado na região interproximal de cada intermediário, já simulando o que será a nova papila periimplantar. São realizadas as suturas nesses pedículos na região interproximal. Essa técnica pode ser utilizada tanto para implantes unitários quanto para implantes múltiplos ${ }^{20}$.

Técnica de Tinti e Benfenati: Essa técnica é indicada para áreas que serão colocados mais de dois implantes adjacentes. É feita uma incisão linear de distal para mesial na região do palato, um pouco abaixo de onde estão situados os implantes, estendendo $5 \mathrm{~mm}$ para distal e mesial, à frente dos implantes, ou, quando há dentes naturais na área, faz-se uma incisão intra-sulcular. Um retalho total é então deslocado de palatino para vestibular, expondo os parafusos de cicatrização, que serão substituídos pelos intermediários. O retalho deslocado para vestibular é suturado em rampa, ficando de 5 a $6 \mathrm{~mm}$ mais alto em relação ao palato. Após 4 a 5 semanas, no segundo estágio cirúrgico, é feita uma gengivectomia por vestibular na região dos intermediários, para dar a forma de papila²1.

Enxerto de tecido conjuntivo: Com o objetivo de conseguir uma espessura maior do tecido gengival, foi descrita, em 2007, uma técnica de enxerto de tecido conjuntivo, usando a técnica da tunelização ${ }^{22}$. Nessa técnica realizam-se duas incisões horizontais na área receptora, a primeira na crista vestibular do rebordo, e realizada o aprofundamento desta incisão até o fundo do vestíbulo dividindo o retalho mucoperiósteo. O mesmo é afastado para preparar o espaço para receber o enxerto conjuntivo. Realiza-se a mensuração da profundidade para a localização da segunda incisão no fundo de vestíbulo. A área de eleição é a da abóbada palatina. Nela é feita uma incisão profunda e perpendicular ao longo eixo dos dentes, distante $3 \mathrm{~mm}$ do sulco gengival. Em seguida realiza-se uma manobra cirúrgica dividindo o tecido conjuntivo do epitélio em direção apical e incisando nas laterais e apicalmente do retalho. São descolados o periósteo com o conjuntivo conseguindo a soltura e remoção do mesmo. 0 osso palatino é recoberto com o tecido epitelial dividido remanescente e suturado. São passados dois fios de sutura no enxerto conjuntivo, um em cada extremidade, para levar o enxerto à posição interposta. Após o enxerto de tecido conjuntivo estar devidamente posicionado no leito cirúrgico estabiliza-se ele com um ponto simples na região mediana, e os fios de tracionamento são removidos. Finalmente, realizam-se as suturas das incisões horizontais, fechando a loja cirúrgica. Essa técnica da tunelização é indicada para corrigir defeitos de Classe I pequenos, moderados e amplos.

Sutura de contenção de papila: A utilização dessa técnica se aplica ao tratamento com implantes em alvéolos cicatrizados e utilizando-se de provisórios imediatos. Faz-se uma incisão em forma de W iniciando na região proximal no aspecto mesial dos dentes vizinhos à área edêntula. Estas incisões seguem em direção mésio-palatina e são unidas por uma segunda incisão em forma de parábola com o vértice voltado para vestibular. A execução correta da incisão é fundamental ao sucesso da técnica, pois todo o tecido deslocado do palato será colocado em íntimo contato com a face vestibular do provisório, onde os vértices formados pelo encontro das duas incisões constituirão as papilas interproximais. Com o tecido sobreposto ao provisório, pinçamos a papila e transferimos a mesma em sentido vestibular, ou seja, da face interna (formada por tecido conjuntivo) para a face externa (formada por tecido epitelial). O fio de sutura passa em íntimo contato com a face cervical do dente vizinho e passa pela proximal com o dente seguinte. É dado um nó simples na mesial do ângulo do dente vizinho. Com isso, nenhuma tensão é aplicada sobre a papila e a sua posição é perpetuada. Após 10 dias, as suturas são removidas e o tecido completará a cicatrização em aproximadamente 4 semanas. 0 manuseio do espaço interproximal, utilizando-se desta técnica de incisão e sutura, resultará numa reconstrução da papila interproximal e contorno vestibular satisfatórios, além de uma maior quantidade de tecido queratinizado, o que resultou em um melhor mecanismo de defesa da mucosa periimplantar ${ }^{23}$.

Retalho de espessura parcial reposicionado apicalmente: Faz-se uma incisão palatina na direção mésio-distal e o retalho é descolado. Mantém os tecidos gengivais tanto mesialmente quanto distalmente no espaço interproximal. $O$ retalho é reposicionado apicalmente no aspecto vestibular e suturado. A superfície da ferida do palato epiteliza aproximadamente em 2 semanas $^{24}$ (Ver Figura 4). 
Figura 4 - Retalho de espessura parcial reposicionado apicalmente.

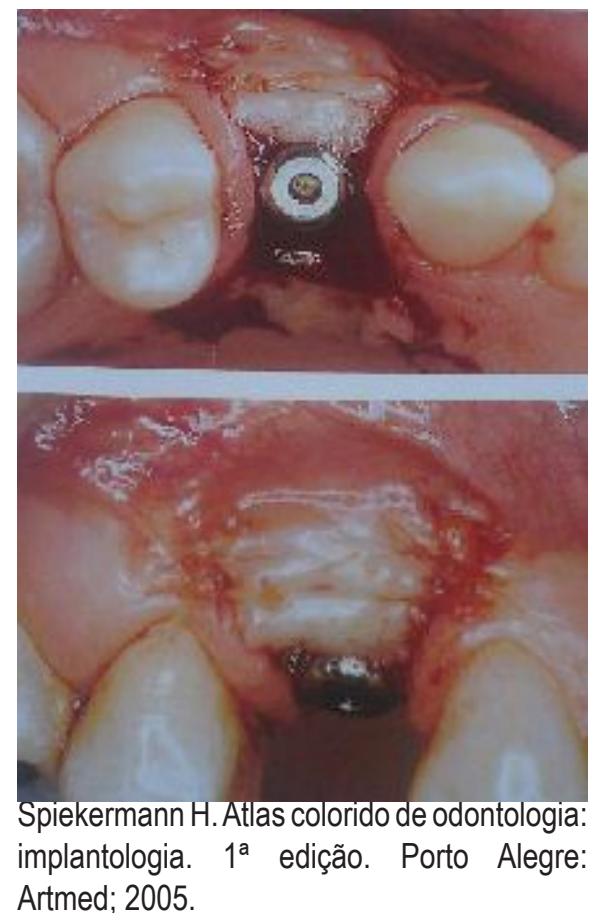

Cicatrizadores e componentes protéticos: Alguns fatores, relacionados à Implantodontia estética, estão intimamente ligados aos pilares, emergentes ou abutments que, ao longo do tempo, sofreram grandes transformações, buscando soluções estéticas adequadas. Os pilares metálicos ganharam popularidade após a introdução do pilar Ucla que permite a individualização através de fundição, suportando prótese cimentada ou parafusada. Uma variedade de formas permitiu que pilares preparáveis de titânio (TiAdapt ${ }^{\circledR}$, Nobel Biocare ${ }^{\circledR}$; Anatomic abutment ${ }^{\circledR}$, SteriOss ${ }^{\circledR}$; PrepTite ${ }^{\circledR}$, 3i/lmplant Innovations ${ }^{\circledR}$, etc) tivessem o mesmo propósito. Em alguns casos, a correta seleção de um pilar de titânio e sua individualização permite a obtenção de uma restauração com perfil de emergência e estética aceitável. Porém, em casos com margem de gengiva livre muito fina, corre-se o risco da região cervical ficar com um halo escuro visível devido à cor metálica do pilar, impedindo a difusão e reflexão da luz. A necessidade estética e o desejo de não se ter estruturas metálicas são fatores que enfatizaram a importância dos sistemas cerâmicos. Componentes cerâmicos têm sido introduzidos por muitos fabricantes, proporcionando pilares mais estéticos que os metálicos. Os tipos disponíveis são: Alumina, Alumina/Zircônia e Zircônia. Esses pilares podem ser classificados em: pré-fabricados e personalizados ${ }^{25}$.

O pilar Ucla foi introduzido por Lewis em 1998 e pode ser utilizado tanto para próteses cimentadas quanto para restaurações parafusadas. Pode-se restaurar casos unitários, utilizando copings anti-rotacionais, parciais e totais empregando copings rotacionais. Este pilar possui coifas calcináveis totalmente em plástico, com sua base pré-usinada em metal nobre ou ligas de metal básico. O pilar Easy Abutment e o Ceraone são indicados para restaurações cimentadas unitárias e pequenas pontes. Podem-se utilizar coroas metalocerâmicas e peças de cerâmica pura. Os pilares preparáveis são pilares que possuem um corpo pré-fabricado, porém permitem que o profissional faça um preparo de suas paredes e término cervical para individualização dos casos. São pilares indicados para próteses unitárias cimentadas. Tais pilares são fabricados tanto em titânio quanto em zirconia ${ }^{26}$.

\section{Discussão}

A exigência estética por parte do paciente está cada vez mais apurada. Quando se trata de reabilitar o paciente com implantes osseointegráveis, na maioria dos casos, a expectativa é ainda maior. Para atender tais expectativas, devese ter conhecimento anatômico dos tecidos periimplantares para entender as várias correlações entre o tecido ósseo, mucosas, implante e prótese. Nas regiões edêntulas, a maioria do rebordo alveolar é acometida por alterações óssea e gengival devido ao trauma cirúrgico, a própria remodelação fisiológica do tecido ósseo e, em determinados casos, pela prótese utilizada anteriormente agravando a atrofia da região $0^{1,6,7,10,15,19,22}$. 
Alguns fatores devem ser observados antes do início do tratamento: volume de tecido necessário para eliminar a deformidade do rebordo, tipo de enxerto ou implante a ser utilizado, localização do sítio doador do enxerto, número e tempo entre vários procedimentos do tratamento, desenho da prótese provisória, tecido desejado, desenho do guia cirúrgico, possíveis problemas com descoloração do tecido e obtenção da cor do tecido desejado ${ }^{15,22}$.

A excelência da estética se deve principalmente ao planejamento cirúrgico e execução de manobras pré-cirúrgicas. Assim, o planejamento se torna requisito obrigatório, pois através dele vamos determinar as manobras que cada caso necessita para chegarmos a um resultado estético satisfatório ${ }^{2,8,10}$.

A ausência de mucosa ceratinizada pode comprometer a sobrevida do implante ${ }^{4}$. Um mínimo de $2 \mathrm{~mm}$ de tecido ceratinizado é necessário para conseguirmos saúde perfeita dos tecidos que circundam o implante5. Já, outros autores sugerem que menos de $1 \mathrm{~mm}$ de tecido ceratinizado pode ser adequado, desde que a placa bacteriana esteja bem controlada 4

Entretanto, em 2006, afirmou-se que a presença da faixa de gengiva ceratinizada, não tem sido considerada um pré-requisito a sobrevida do implante, contudo a sua presença traz as seguintes vantagens: a margem gengival se mantém constante e resistente à recessão; melhor estética, pois auxilia na formação de papilas; facilita a higiene oral; a manipulação cirúrgica se torna mais fácil; facilita procedimentos de moldagem; oferece resistência aos danos causados pela ação mecânica da escovação. Há diferença na espessura do tecido gengival, e, portanto, diferentes biótipos gengivais. A falta de espessura gengival pode causar transparência na área de inserção do implante, ocasionando translucidez na prótese sobre-implante 9 .

Uma das condutas clínicas mais satisfatórias e simples de ser realizada é o direcionamento gengival por compressão suave para formação da papila ${ }^{9,5,11,19}$. Além disso, em outro estudo ${ }^{13}$, são citadas vantagens funcionais quanto à prevenção do acúmulo de placa proporcionada pelo contato íntimo entre tecidos e pôntico, com consequente ausência de sinais visíveis de inflamação.

Um dos procedimentos mais indicados para aumentar a espessura gengival parece ser o enxerto gengival. Foi concluído que a cirurgia plástica gengival pode resultar em aumento de espessura da mucosa principalmente em locais em que o fenótipo é delgado ${ }^{14}$. 0 enxerto de tecido conjuntivo pode reparar defeitos no rebordo, restaurar contornos originais pelo aumento da altura e espessura dos tecidos moles ${ }^{7}$. Os enxertos de tecido conjuntivo subepitelial vêm sendo considerados a técnica padrão em cirurgia plástica periodontal já que a sua utilização permite um duplo suprimento sanguíneo do enxerto e minimiza problemas com relação à coloração do tecido após cicatrização ${ }^{1,22}$.

A técnica da dobra cirúrgica é um procedimento mais simples e menos invasivo que as técnicas de enxerto gengival livre podendo ser facilmente realizada pelo clínico. Esta técnica não reverte em custos para o cirurgião ou paciente pois dispensa o uso de biomateriais, evita a morbidade de um leito doador e receptor como nas técnicas de enxertia gengival e há um ganho de volume gengival, favorecendo a estética na prótese ${ }^{17,18}$. Porém, 0 trabalho necessita de acompanhamento longitudinal para avaliação da estabilidade e manutenção dos tecidos gengivais modificados por esta técnica, a médio e longo prazo.

A substituição de dentes comprometidos por implantes imediatos em áreas estéticas é cada vez mais freqüente. Entretanto, a remodelação dos tecidos periimplantares após a exodontia, ainda que seguida da colocação imediata do implante, pode comprometer o resultado estético do tratamento ${ }^{10,12}$.

A carga imediata quando bem indicada, além de trazer um maior conforto ao paciente, por evitar o uso de restaurações provisórias removíveis e encurtar o tempo de tratamento, pode também ser uma das melhores maneiras de condicionamento dos tecidos periimplantares ${ }^{8,11}$. Regras básicas como: seleção do diâmetro correto da cabeça do implante, distância entre eles e posicionamento tridimensional dos mesmos são fundamentais para o êxito estético do tratamento, sendo o guia cirúrgico uma ferramenta indispensável para a sua obtenção.

\section{Conclusão}

Um plano de tratamento bem realizado e um eficaz controle de placa constituem um pré-requisito fundamental para 0 sucesso da terapia com implantes.

De um modo geral, há diferentes etapas onde se pode intervir nos tecidos periimplantares: antes da colocação dos implantes, simultaneamente à colocação dos mesmos, durante a fase de osseointegração e na reabertura dos implantes. 
O sucesso do aumento de tecido mole depende da preparação cuidadosa da área receptora, seleção de uma adequada área doadora, preparação meticulosa do enxerto, precisão no posicionamento do enxerto e técnica de sutura adequada.

A exigência estética varia de um paciente para outro, e o resultado estético depende da forma, do contorno, do limite cervical, do perfil de emergência da restauração implanto suportada e da qualidade e quantidade da mucosa periimplantar.

Com base na revisão de literatura, não há diferença entre as técnicas para o sucesso, porém existem condições individuais e limitações que devem ser avaliadas caso a caso criteriosamente.

\section{Referências biliográficas}

1. Pelegrine AA, Costa CE, Sendyk WR. Enxerto de tecido conjuntivo: uma alternativa para alcançar a estética periimplantar. Relato de caso. Implantnews. 2006; 3(3): 249-254.

2. Lindhe J. Tratado de periodontia clínica e implantologia oral. Rio de Janeiro: Guanabara Koogan; 1997.

3. Parnaíba, ACO. Condicionamento gengival em prótese fixa sobre dentes e implantosuportada. Monografia da FUNORTE, Três Corações/MG, 2012.

4. Nascimento, P. L. A.; Rocha, D. N.; Maia, J. O. ; Coimbra, L. M. R.; Dias, A. H. M.. Estética perimplantar por meio de condicionamento gengival. RGO. Revista Gaúcha de Odontologia. 2012. V. 60, N. 4.

5. Oliveira JA, Ribeiro EP, Conti PC, Valle AL, Pegoraro LF. Condicionamento gengival: estética em tecidos moles. Rev Facul Odont Bauru. 2002; 10(2): 99-104.

6. Davarpanah M. Manual de implantodontia Clinica. Artmed; 2003. 337p.

7. Askary AS. Cirurgia estética reconstrutiva na implantodontia. São Paulo: Santos, 2004.

8. Camargo LO, Tortamano P, Missaka R. Conduta de planejamento em setores estéticos associados à carga imediata Descrição de caso clínico. Implantnews. 2005; 2(2): 132-136.

9. Francischone CE, Nary H, Filho, Matos DA, Lira HG, Neves JB, Vasconcelos LW, Paz LG, Duarte LR. Osseointegração e o Tratamento Multidisciplinar. São Paulo: Quintessence; 2006; 320p.

10. Tosta M, Ferraz P, Moura GS Filho, Guerra L, Saraceni CH, Tosta M et al. Previsibilidade em áreas estéticas: 0 conceito da abordagem imediata. Rev Dental Press Periodontia Implantol. 2007; 1(1): 95-111.

11. Filho JS, Encarnação IC, Silva AP, Dotto CA. Como conseguir adequada estética gengival em implantes unitários imediatos: relato de caso clínico. Perionews. 2007; 1(3): 219-223.

12. Gomes CE, Kock A, Sherer M, Antunes D, Salvoni AD, Wassall T. Exodontia múltipla preventiva e instalação de implantes cônicos, utilizando a técnica de múltiplas incisões circulares na preservação do rebordo alveolar e obtenção de perfil gengival estético. Implantnews. 2007; 4(6): 698-703.

13. Kim TH, Cascione D, Knezevic A. Simulated tissue using a unique pontic design: a clinical report. ; J Prosthet Dent. 2009; 102(4): 205-210.

14. Speroni S, Cicciu M, Maridati P, Grossi GB, Maiorana C. Clinical investigation of mucosal thickness stability after soft tissue grafting around implants: A 3-year retrospective study. Indian J Dent Res. 2010; 21(4): 474-479.

15. Simon Z, Rosenblatt A. Challenges in achieving gingival harmony. J Calif Dent Assoc. 2010; 38(8): 583-590.

16. Pimentel AC, Pires CS, Silva EL, Rios MA, Lacerda PN. Carga Imediata em Implantes Unitários - Relato de dois casos clínicos. Implantnews. 2007; 4(4): 433-436.

17. Motta, S.; Camilo, F.; Técnica de dobra cirúrgica para reabertura de implantes osseointegrados;Rio de Janeiro. [capturado em Nov. 2007] Disponível em www.clivo.com.br/pdf/dobra_cirur.pdf.

18. Togashi AY. Técnica de aumento do tecido mole peri-implantar. Rev Paranaense Perio Implant. 2003; 1(1): 25-31.

19. Nemcovsky CE, Moses O, Artzi Z. Interproximal paillae reconstruction in maxillare implants. J Periodontol. 2000; 17(2): 308-314.

20. Palacci P, Ericsson I. Esthetic implant dentistry: Soft and hard tissue management. Chicago: Quintessence; 2001.

21. Tinti C, Benfenati SP. The rampe mattress suture: a new suturing technique combined with a surgical procedure to obtain papillae between implants in the bucal area. Int J Periodontics Restorative Dent. 2002; 22(1): 505-510.

22. Curvelo, JC, Jr, Magalhães JC, Zaffalon GT, Smanio H, Neto, Anselmo SM. Tratamento cirúrgico do defeito do rebordo para otimizar o perfil de emergência em implantes osseointegrados. Implantnews. 2007; 4(3): 279-284. 
23. Barbara AB, Martins MR, Barcelos MJ, Perrota LA. Sutura de contenção de papila: uma abordagem cirúrgica em prótese unitária imediata sobre implante. Implantnews. 2006; 3(1): 49-54.

24. Spiekermann H. Atlas colorido de odontologia: implantologia. $1^{\text {a }}$ edição. Porto Alegre: Artmed; 2005.

25. Bottino MA, Faria R, Buso L, Silgtz F. Implantodontia estética: O desenvolvimento de um novo pilar cerâmico. Implantnews. 2005; 2(6): 592-600.

26. Herbstrith RM, Oshima HM, Teixeira ER, Gruendling CA, Coelho LF. Alternativas estéticas para casos unitários com a utilização de pilares pré-fabricados. Implantnews. 2007; 4(1): 59-62.

\section{Gustavo Adolfo Terra Quesada}

Endereço para correspondência - Rua Professor Braga, n.45, apto 801. Bairro Centro, CEP: 97015-530, Santa Maria, RS, Brasil.

E-mail: gquesada@via-rs.net

Lattes: http://lattes.cnpq.br/1601226679926322

Melissa Rizzardi - merizzardi@hotmail.com

Letícia Jung Franciscatto - leticiafranciscatto@hotmail.com

Fabíola Rossato Arrais - fabiarrais@hotmail.com

Enviado em 22 de maio de 2012.

Publicado em 20 de janeiro de 2014. 